Article

\title{
Ca-Doped $\mathrm{CrO}_{X} / \gamma-\mathrm{Al}_{2} \mathrm{O}_{3}$ Catalysts with Improved Dehydrogenation Performance for the Conversion of Isobutane to Isobutene
}

\author{
Guangjian Wang ${ }^{1}$, Ning Song ${ }^{1}$, Kai Lu ${ }^{1}$, Wentai Wang ${ }^{2}$, Liancheng Bing ${ }^{1}$, Qinqin Zhang ${ }^{3}{ }^{(\mathbb{D}}$, \\ Haitao Fu ${ }^{4}$, Fang Wang ${ }^{1}$ and Dezhi Han ${ }^{1, *(D)}$ \\ 1 State Key Laboratory Base of Eco-Chemical Engineering, College of Chemical Engineering, \\ Qingdao University of Science and Technology, Qingdao 266042, China; wgjnet@126.com (G.W.); \\ songning316@163.com (N.S.); 1k6197@126.com (K.L.); blc0633@126.com (L.B.); fwang@qust.edu.cn (F.W.) \\ 2 Key Laboratory of Marine Chemistry Theory and Technology, Ministry of Education, College of Chemistry \\ and Chemical Engineering, Ocean University of China, Qingdao 266100, China; wentaiwang@ouc.edu.cn \\ 3 Shandong Provincial Key Laboratory of Biochemical Engineering, College of Marine Science and Biological \\ Engineering, Qingdao University of Science and Technology, Qingdao 266042, China; qqzhang@qust.edu.cn \\ 4 School of Metallurgy, Northeastern University, Shenyang 110819, China; fuht@smm.neu.edu.cn \\ * Correspondence: handzh@qust.edu.cn; Tel.: +86-532-8402-2879
}

Received: 20 October 2019; Accepted: 15 November 2019; Published: 16 November 2019

\begin{abstract}
The dehydrogenation of low-carbon alkane to obtain olefins is an effective way to meet the steadily increasing demand of these building blocks in chemical industry. In this study, Ca-doped $\mathrm{CrO}_{\mathrm{x}} / \gamma-\mathrm{Al}_{2} \mathrm{O}_{3}$ catalysts were fabricated via a one-pot method by employing $\mathrm{Cr}(\mathrm{OH})_{3}$ as the precursor, and their catalytic performances were tested in the dehydrogenation of isobutane to isobutene (DITI) process. The prepared catalysts were intensively characterized by $\mathrm{XRD}, \mathrm{SEM}, \mathrm{NH}_{3}-\mathrm{TPD}, \mathrm{H}_{2}-\mathrm{TPR}$, low-temperature $\mathrm{N}_{2}$ adsorption-desorption, etc. These characterization results indicated that the doping of $\mathrm{Ca}$ into the $\mathrm{CrO}_{x} / \gamma-\mathrm{Al}_{2} \mathrm{O}_{3}$ catalysts could tune the acidity properties of the prepared catalysts and enhance the interaction between the active species and support. The Ca-doped $\mathrm{CrO}_{\mathrm{x}} / \gamma-\mathrm{Al}_{2} \mathrm{O}_{3}$ catalysts, especially the Ca2-Cr $/ \gamma-\mathrm{Al}_{2} \mathrm{O}_{3}$ catalyst with a Ca doping of $2 \mathrm{wt} \%$, exhibited a superior catalytic performance in the DITI process in comparison with the undoped catalyst.
\end{abstract}

Keywords: calcium; chromium oxide; interaction; isobutane dehydrogenation

\section{Introduction}

In recent years, the supply of low-carbon olefins obtained from conventional routes, such as steam cracking and catalytic cracking, have not been able to satisfy the rapid development of the global economy and the petrochemical industry [1]. Moreover, these conventional processes also have the disadvantages of a large energy consumption and a low olefin yield [2,3]. Alternatively, the dehydrogenation of low-carbon alkane seems to be an effective way to obtain olefins by addressing the fast deletion of the crude oil reservoir. Among these olefins, isobutene is one of the major building blocks in the petrochemical industry for producing methyl tert-butyl ether (MTBE), methyl methacrylate (MMA), tert-butyl alcohol (TBA) and other important intermediates [4-6]. Compared to the oxidative dehydrogenation technique, the non-oxidative dehydrogenation of isobutane has the merits of low energy consumption and safe and reliable operation; as such, it is considered an attractive process to meet the increasing demand for isobutene [7]. However, the isobutane dehydrogenation reaction is an endothermic process that requires relatively low pressure and high temperature to achieve the high conversion of isobutane and high selectivity of isobutene [7-11]. The high reaction temperature inevitably results in the thermal cracking of the isobutane and the fast deactivation of the catalyst 
due to severe carbon deposition [12]. Therefore, the objective of the present and future studies is to modify the conventional catalysts or explore novel catalysts for the dehydrogenation of isobutane to isobutene (DITI).

Many metal material catalysts, such as platinum-based, chromium-based, vanadium-based and molybdenum-based catalysts, have been intensively investigated and reported on in regard to the dehydrogenation reaction [13-16]. In particular, chromium-based catalysts have been found to exhibit high catalytic activity for the dehydrogenation of low-carbon alkanes and have been widely used in commercial processes $[17,18]$. The addition of promoters (alkali metals or rare earth metals) could bring a positive effect for promoting both the activity and selectivity of chromium-based dehydrogenation catalysts $[7,18]$. The introduction of the Ga element into the chromium-based catalyst has been shown to enhance the catalyst stability at least in 60 cycles without changes in catalytic activity and selectivity during tests of isobutane dehydrogenation [19]. The addition of nickel has been shown to lead to the formation of low-valent chromium as well as the decrease of the $\mathrm{Cr}^{6+}$ content for the improvement of the catalytic activity [20]. The addition of the K additive has been shown to dramatically reduce the acidity of catalysts, thus decreasing the rate of coke formation. However, the addition of the $\mathrm{K}$ species has also exhibited a negative impact on the dehydrogenation process due to the poison of some Lewis acid sites [21], and it has been found in the oxidative dehydrogenation of isobutane that the alkaline-earth metal $\mathrm{Ca}$ additive with a mild alkaline property could decrease the acidity of chromium-based catalysts and weaken the adsorption of formed isobutene, thus facilitating the desorption process [22]. However, the effect of Ca doping on the catalytic DITI performance over the chromium-based catalysts has rarely been reported.

Additionally, catalyst preparation methods can significantly influence the dispersion of active sites as well as the interaction between the support and active phases [23-26]. Bai et al. employed one-step process to synthesize a $\mathrm{Cr}(\mathrm{OH})_{3}$ precursor for the subsequent preparation of $\mathrm{Cr}_{2} \mathrm{O}_{3}$ catalysts with enhanced catalytic performance in the DITI reaction [27]. The supramolecular templating technique has also been applied to fabricate the mesoporous $\mathrm{Cr} / \mathrm{Al}_{2} \mathrm{O}_{3}$ catalysts, which possess a high catalytic dehydrogenation performance for light alkane due to the high dispersion of chromium oxide [28]. Therefore, an exploration of the novel precursor and support could be crucial for improving the catalytic DITI performance of chromium-based catalysts.

Moreover, in heterogeneous catalysis, the metal-support interaction could dramatically influence the catalytic performance of the prepared catalysts. Therefore, the modification of the metal-support interaction can be employed as a tool for designing novel supported metal catalysts with enhanced performance. Several synthetic strategies for the control of the metal-support interaction have been reported, such as the modification of the support (support composition, morphology, doping and surface modifications), the modification of the metal component (metal particle' size and composition), and the post-treatment of the as-prepared catalyst (thermal, reducing agent, reduction-oxidation cycles, etc.) [29]. Among these techniques, the doping of the support with elements seems to be the simple and effective way to tune the metal-support interaction of the supported metal catalysts. For instance, the doping $\mathrm{Mg}^{2+}$ or $\mathrm{La}^{3+}$ of $\gamma-\mathrm{Al}_{2} \mathrm{O}_{3}$ has been shown to prevent the formation of the undesired mixed oxide and to adjust the typically acidic properties of $\gamma-\mathrm{Al}_{2} \mathrm{O}_{3}[30,31]$. In this work, $\mathrm{Ca}^{2+}$ was employed to modify the $\gamma-\mathrm{Al}_{2} \mathrm{O}_{3}$ support in preparationof $\mathrm{Ca}$-doped $\mathrm{CrO}_{\mathrm{x}} / \gamma-\mathrm{Al}_{2} \mathrm{O}_{3}$ catalysts for the conversion of isobutane to isobutene.

\section{Results}

\subsection{Isobutane Dehydrogenation Performance}

The catalytic DITI performances of the fabricated catalysts with time on stream are shown in Figure 1. It can be observed that the isobutane conversions for all catalysts gradually decreased with reaction time. For instance, the initial isobutane conversion over the $\mathrm{Cr} / \gamma-\mathrm{Al}_{2} \mathrm{O}_{3}$ catalyst prepared by the one-pot method was $56.5 \%$, and reduced to $38.7 \%$ after $10 \mathrm{~h}$ reaction, which was better 
than that of the $\mathrm{C}-\mathrm{Cr} / \gamma-\mathrm{Al}_{2} \mathrm{O}_{3}$ catalyst (see the definition in the Materials and Methods section) fabricated by the conventional method. Moreover, the addition of $\mathrm{Ca}$ into the $\mathrm{Cr} / \gamma-\mathrm{Al}_{2} \mathrm{O}_{3}$ catalysts exhibited the expected positive effect on both of the isobutane conversion and the isobutene selectivity. The isobutane conversions of $\mathrm{Ca} 1-\mathrm{Cr} / \gamma-\mathrm{Al}_{2} \mathrm{O}_{3}, \mathrm{Ca} 2-\mathrm{Cr} / \gamma-\mathrm{Al}_{2} \mathrm{O}_{3}$ and $\mathrm{Ca} 4-\mathrm{Cr} / \gamma-\mathrm{Al}_{2} \mathrm{O}_{3}$ (see the definition in the Materials and Methods section) could be maintained at $>40 \%$ after an investigation of $10 \mathrm{~h}$, indicating that the relatively high stability of the catalysts after the doping of $\mathrm{Ca}$. The results of the selectivity of isobutene over the prepared catalysts illustrated the same trend as the results of the isobutane conversion. For example, except for the $\mathrm{Ca} 4-\mathrm{Cr} / \gamma-\mathrm{Al}_{2} \mathrm{O}_{3}$ catalyst, the selectivities of isobutene over all the Ca-doped catalysts increased with the increase in the doping amount of $\mathrm{Ca}$, and, compared with the other Ca-doped catalysts, the Ca2-Cr $/ \gamma-\mathrm{Al}_{2} \mathrm{O}_{3}$ catalyst with the optimum Ca doping of $2 \mathrm{wt} \%$ showed the stable and highest selectivity of isobutene $(>83 \%)$ under the investigation time. Moreover, the prepared Ca-doped catalysts also exhibited a superior catalytic performance in comparison with the $\mathrm{Cr}_{2} \mathrm{O}_{3} / \gamma-\mathrm{Al}_{2} \mathrm{O}_{3}$ catalysts, which were prepared by the addition of a chelating agent, as reported in our previous work [32]. These results implied that the Ca additive (Ca loading $\leq 2 \%$ ) exhibited a mild alkaline property to tune the acidity of the chromium-based catalysts. In addition, the selectivity of isobutene for all catalysts slowly increased during the initial $3 \mathrm{~h}$ of the dehydrogenation reaction due to the formation of active sites $\left(\mathrm{Cr}^{3+}\right.$ species) over the catalysts.

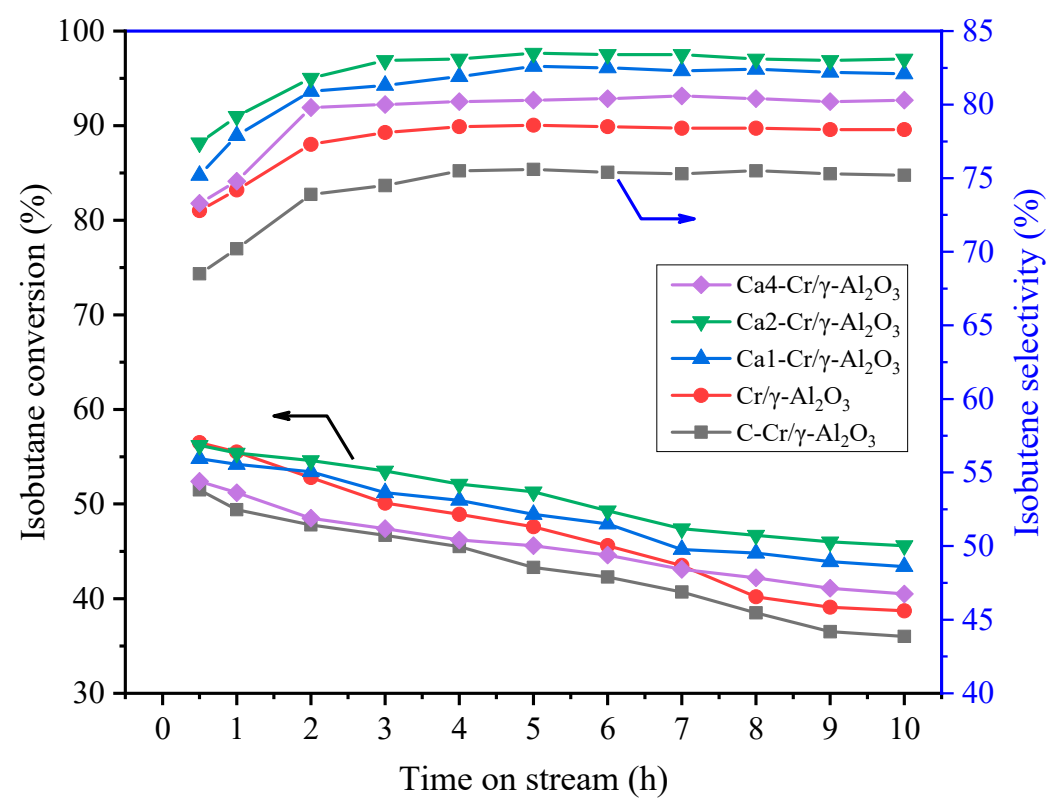

Figure 1. The conversions of isobutane and selectivities of isobutene over different catalysts with time on stream. (Temperature: $550{ }^{\circ} \mathrm{C}$; reactant flow rate: $40 \mathrm{~mL} \mathrm{~min}^{-1}$; catalyst mass: $5 \mathrm{~g}$ ).

\subsection{XRD Analysis}

Figure 2 shows the XRD patterns of the prepared catalysts with and without the doping of Ca. It can be seen that all samples exhibited three broad diffraction peaks at about $37.6^{\circ}, 45.5^{\circ}$ and $67.3^{\circ}$, with respect to the characteristic $\gamma-\mathrm{Al}_{2} \mathrm{O}_{3}$ phase (JCPDS Card No. 10-0425) [33,34]. Compared to the conventional $\mathrm{C}-\mathrm{Cr} / \gamma-\mathrm{Al}_{2} \mathrm{O}_{3}$ catalyst, the chromium oxide $\left(\mathrm{Cr}_{2} \mathrm{O}_{3}\right)$ phase with low crystallinity emerged in the $\mathrm{Cr} / \gamma-\mathrm{Al}_{2} \mathrm{O}_{3}$ catalyst prepared by employing $\mathrm{Cr}(\mathrm{OH})_{3}$ as the new precursor. Furthermore, it has been reported that many peaks of $\mathrm{Cr}_{2} \mathrm{O}_{3}$ and $\mathrm{CaCrO}_{4}$ are coincident [22]. After the doping of $\mathrm{Ca}$ into the $\mathrm{Cr} / \gamma-\mathrm{Al}_{2} \mathrm{O}_{3}$ catalysts, there were no obvious changes in XRD spectra of the $\mathrm{Ca} 1-\mathrm{Cr} / \gamma-\mathrm{Al}_{2} \mathrm{O}_{3}$, $\mathrm{Ca} 2-\mathrm{Cr} / \gamma-\mathrm{Al}_{2} \mathrm{O}_{3}$ and $\mathrm{Ca} 4-\mathrm{Cr} / \gamma-\mathrm{Al}_{2} \mathrm{O}_{3}$ catalysts; even the addition of $\mathrm{Ca}$ was up to $4 \mathrm{wt} \%$, suggesting that the chromate phase $\left(\mathrm{CaCrO}_{4}\right)$ was absent or below the detection limit of the XRD technique. Additionally, no other new crystalline phases could be found in the XRD patterns. 


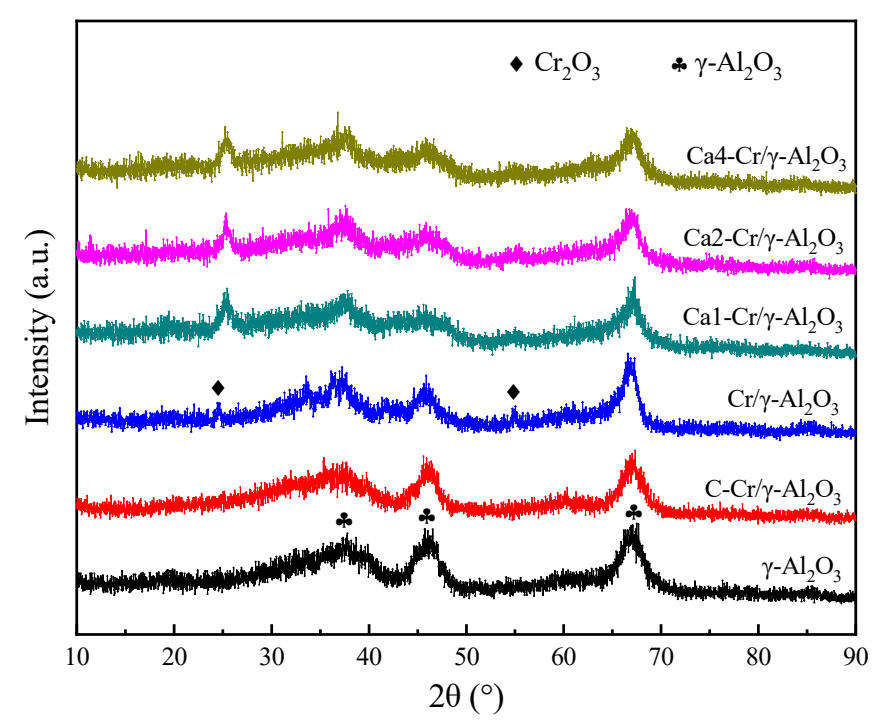

Figure 2. XRD patterns of the fabricated catalysts.

\subsection{Textural Properties}

Figure 3 illustrates the SEM images of the prepared catalysts for the morphology investigation. It can be seen that all catalysts possess almost the same morphologies with the aggregation of the primary clusters to form the catalyst particles, implying that the addition of Ca could not influence the basic morphologies of the catalyst. The results of the low-temperature $\mathrm{N}_{2}$ adsorption-desorption characterization from Table 1 indicate that the introduction of $\mathrm{Cr}$ into the $\gamma-\mathrm{Al}_{2} \mathrm{O}_{3}$ support resulted in a significant decrease of the surface area and pore volume of the obtained catalysts, especially for the $\mathrm{C}-\mathrm{Cr} / \gamma-\mathrm{Al}_{2} \mathrm{O}_{3}$ catalyst prepared by the conventional method. This could be ascribed to the blocking of the pore channel in $\gamma-\mathrm{Al}_{2} \mathrm{O}_{3}$ by the introduced chromium oxide. However, the Ca-doped catalysts exhibited a similar surface area of about $210 \mathrm{~m}^{2} \mathrm{~g}^{-1}$, which was slight decrease in comparison with the undoped $\mathrm{Cr} / \gamma-\mathrm{Al}_{2} \mathrm{O}_{3}$ catalyst fabricated through the one-pot method, suggesting the well dispersion of the $\mathrm{Ca}$ in the doped catalysts.

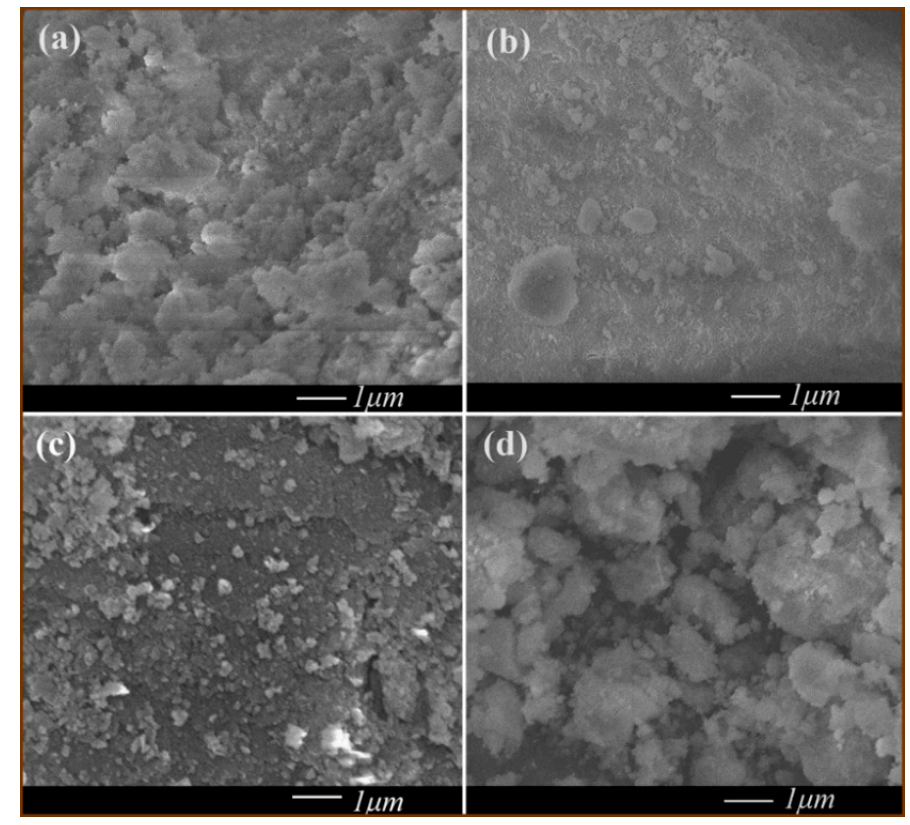

Figure 3. SEM images of the prepared catalysts. (a) $\mathrm{C}-\mathrm{Cr} / \gamma-\mathrm{Al}_{2} \mathrm{O}_{3},(\mathbf{b}) \mathrm{Ca} 1-\mathrm{Cr} / \gamma-\mathrm{Al}_{2} \mathrm{O}_{3}$, (c) $\mathrm{Ca} 2-\mathrm{Cr} / \gamma-\mathrm{Al}_{2} \mathrm{O}_{3}$, and (d) $\mathrm{Ca} 4-\mathrm{Cr} / \gamma-\mathrm{Al}_{2} \mathrm{O}_{3}$. 
Table 1. Structure parameters of different catalysts.

\begin{tabular}{ccc}
\hline Sample & $\mathbf{S}_{\text {BET }} \mathbf{( m}^{\mathbf{2}} \mathbf{g}^{-\mathbf{1})}$ & $\mathbf{V}_{\text {total }}\left(\mathbf{c m}^{\mathbf{3}} \mathbf{g}^{\mathbf{- 1}}\right)$ \\
\hline$\gamma-\mathrm{Al}_{2} \mathrm{O}_{3}$ & 265 & 0.43 \\
$\mathrm{C}-\mathrm{Cr} / \gamma-\mathrm{Al}_{2} \mathrm{O}_{3}$ & 127 & 0.35 \\
$\mathrm{Cr} / \gamma-\mathrm{Al}_{2} \mathrm{O}_{3}$ & 221 & 0.41 \\
$\mathrm{Ca} 1-\mathrm{Cr} / \gamma-\mathrm{Al}_{2} \mathrm{O}_{3}$ & 213 & 0.40 \\
$\mathrm{Ca} 2-\mathrm{Cr} / \gamma-\mathrm{Al}_{2} \mathrm{O}_{3}$ & 210 & 0.39 \\
$\mathrm{Ca} 4-\mathrm{Cr} / \gamma-\mathrm{Al}_{2} \mathrm{O}_{3}$ & 203 & 0.41 \\
\hline
\end{tabular}

\subsection{The Analysis of the Acidity Properties}

The $\mathrm{NH}_{3}$-TPD profiles are depicted in Figure 4 to evaluate the acidity properties of the prepared catalysts. It can be observed that the $\mathrm{C}-\mathrm{Cr} / \gamma-\mathrm{Al}_{2} \mathrm{O}_{3}$ catalyst exhibited the $\mathrm{NH}_{3}-\mathrm{TPD}$ profiles with the two desorption peaks located at about 130 and $390{ }^{\circ} \mathrm{C}$, which could be ascribed to the weak and strong acid sites, respectively. Compared to $\mathrm{C}-\mathrm{Cr} / \gamma-\mathrm{Al}_{2} \mathrm{O}_{3}$ catalyst, the $\mathrm{Cr} / \gamma-\mathrm{Al}_{2} \mathrm{O}_{3}$ catalyst had no obvious peak variation, but it had a slight decrease in the strength of the strong acid sites. Furthermore, after the doping of the $\mathrm{Ca}$ into the catalyst, the low-temperature peaks for $\mathrm{Ca} 1-\mathrm{Cr} / \gamma-\mathrm{Al}_{2} \mathrm{O}_{3}, \mathrm{Ca} 2-\mathrm{Cr} / \gamma-\mathrm{Al}_{2} \mathrm{O}_{3}$ and $\mathrm{Ca} 4-\mathrm{Cr} / \gamma-\mathrm{Al}_{2} \mathrm{O}_{3}$ catalysts shifted to the lower temperature, showing that the doping of $\mathrm{Ca}$ with alkalinity could tune the acidity properties of the prepared catalysts, which accounts for the decrease in the intensity of weak acid sites. Meanwhile, the peaks of the strong acid sites over the doped catalysts also correspondingly decreased. These results imply that the Ca species doped into the catalysts could substantively tune the acidity properties of the prepared catalysts. Previous studies have demonstrated that the strong acid sites could result in side reactions, such as the isomerization and cracking reactions in dehydrogenation process [34-37]. Therefore, the prepared Ca-doped catalysts with relatively weak acid sites exhibited enhanced conversions of isobutane and selectivities of isobutene, especially for $\mathrm{Ca} 2-\mathrm{Cr} / \gamma-\mathrm{Al}_{2} \mathrm{O}_{3}$ with the optimum Ca loading of $2 \mathrm{wt} \%$, as described in the results of Figure 1.

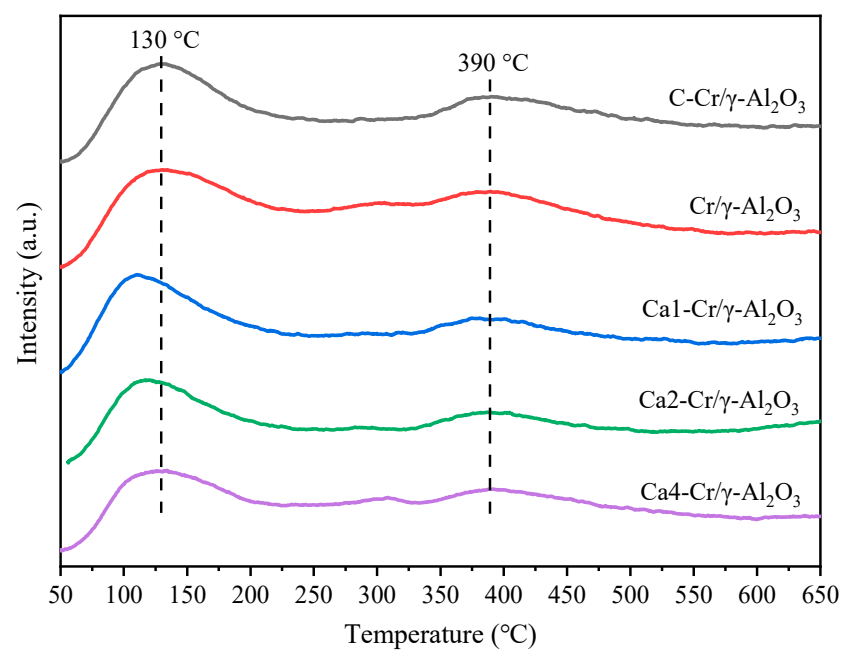

Figure 4. The $\mathrm{NH}_{3}-\mathrm{TPD}$ profiles of the prepared catalysts.

\subsection{The Reduction Behavior}

The reducibility of the Cr species could significantly influence the activity of the DITI catalysts, and the corresponding $\mathrm{H}_{2}$-TPR curves for the prepared catalysts are shown in the Figure 5. It can be observed that the conventional $\mathrm{C}-\mathrm{Cr} / \gamma-\mathrm{Al}_{2} \mathrm{O}_{3}$ catalyst displayed the obvious single reduction peak at about $288^{\circ} \mathrm{C}$, which could be ascribed to the one-step reduction of the $\mathrm{Cr}$ species. Additionally, the reduction peak slightly shifted to high temperature $\left(310{ }^{\circ} \mathrm{C}\right)$ for the $\mathrm{Cr} / \gamma-\mathrm{Al}_{2} \mathrm{O}_{3}$ catalyst fabricated by the one-pot method, indicating the enhancement of the interaction between the $\mathrm{Cr}$ species and $\gamma-\mathrm{Al}_{2} \mathrm{O}_{3}$, as reported in the previous studies [38,39]. Moreover, after the doping of Ca into the catalysts, 
the elevated temperature $\left(>390^{\circ} \mathrm{C}\right)$ of the reduction peak for the doped catalysts suggests the existence of a strong interaction between the $\mathrm{Cr}$ species and the $\gamma-\mathrm{Al}_{2} \mathrm{O}_{3}$ support, which is solid evidence of the positive effect of Ca doping in the DITI catalysts. Generally, one of the main reasons for the deactivation of the DITI catalyst is the weak interaction between the active component and the support $[17,38]$. The existence of the strong interaction in the fabricated Ca-doped catalysts could restrain the over-reduction of active species, thus enabling the survival of the catalysts in the reducing atmosphere of the DITI. Therefore, the appropriate acid intensity and active component-support interaction could be responsible for the superior catalytic performance of the $\mathrm{Ca} 2-\mathrm{Cr} / \gamma-\mathrm{Al}_{2} \mathrm{O}_{3}$ catalyst, which was reflected in the DITI reaction performance in Figure 1.

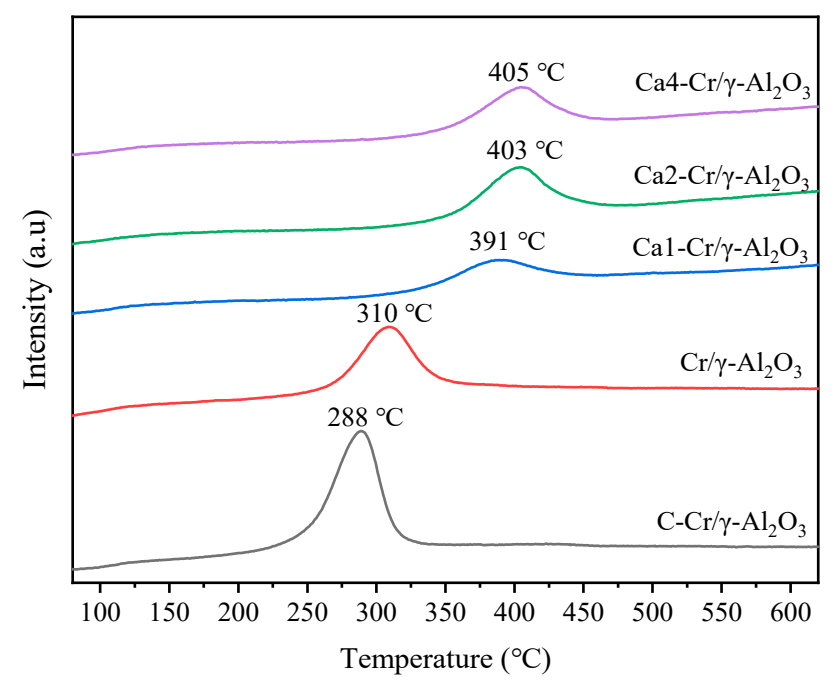

Figure 5. The $\mathrm{H}_{2}$-TPR (temperature programmed reduction) profiles of different catalysts.

\subsection{The TG Analysis of the Spent Catalysts}

Figure 6 shows the TG curves to investigate the coke resistance of the prepared catalysts. It can be seen that there are two obvious stages of the weight loss in these curves. The weight loss in the stage 1 can be ascribed to the removal of the water and volatile organic component in the samples. Additionally, the elimination of deposited coke on the catalysts mainly occurred in Stage 2. After the doping of $\mathrm{Ca}$ into the catalyst, the TG results indicate that the $\mathrm{Ca} 2-\mathrm{Cr} / \gamma-\mathrm{Al}_{2} \mathrm{O}_{3}$ catalyst exhibited improved ability for coke resistance in comparison with the undoped one $\left(\mathrm{Cr} / \gamma-\mathrm{Al}_{2} \mathrm{O}_{3}\right)$.

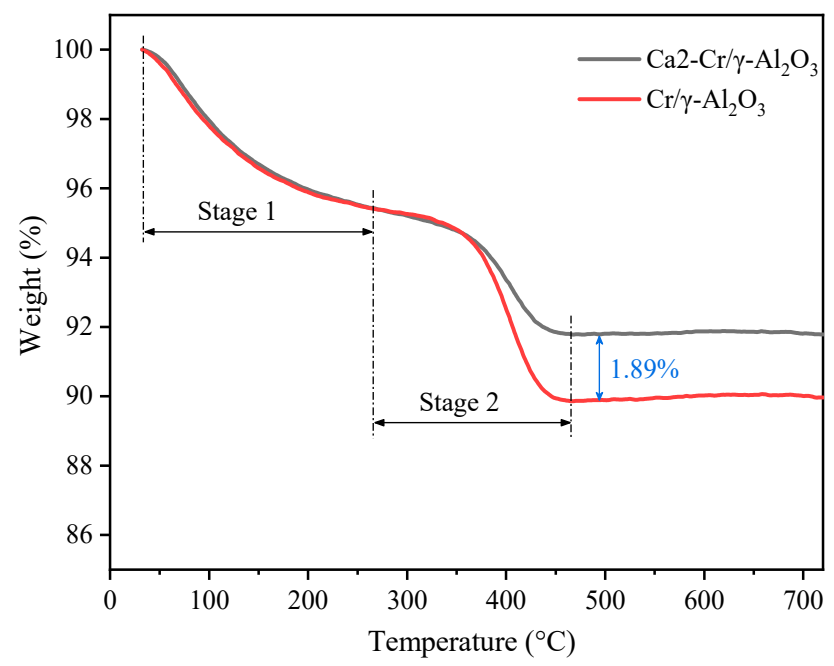

Figure 6. The TG curves of the spent catalysts. 


\section{Materials and Methods}

\subsection{The Preparation of Catalysts}

Chromium chloride hexahydrate $\left(\mathrm{CrCl}_{3} \cdot 6 \mathrm{H}_{2} \mathrm{O}, 98 \%\right)$, sodium borohydride $\left(\mathrm{NaBH}_{4}, 98 \%\right)$, calcium nitrate nonahydrate $\left(\mathrm{Ca}\left(\mathrm{NO}_{3}\right)_{2} \cdot 9 \mathrm{H}_{2} \mathrm{O}, 98 \%\right)$ and ethanol $\left(\mathrm{C}_{2} \mathrm{H}_{5} \mathrm{OH}, 99.7 \%\right)$ were all supplied by Sinopharm, Shanghai, China, and these reagents were used as received without any further purification.

The conventional $\mathrm{CrO}_{\mathrm{x}} / \gamma-\mathrm{Al}_{2} \mathrm{O}_{3}$ catalyst (denoted as $\mathrm{C}-\mathrm{Cr} / \gamma-\mathrm{Al}_{2} \mathrm{O}_{3}$ ) with a $\mathrm{Cr}$ loading of $10 \mathrm{wt} \%$ was prepared by the incipient wetness impregnation method, as described elsewhere [40], and the Ca-doped $\mathrm{CrO}_{x} / \gamma-\mathrm{Al}_{2} \mathrm{O}_{3}$ catalysts with a $\mathrm{Cr}$ loading of $10 \mathrm{wt} \%$ were prepared by employing $\mathrm{Cr}(\mathrm{OH})_{3}$ as the precursor. In the typical process, $2.04 \mathrm{~g}$ of $\mathrm{CrCl}_{3} \cdot 6 \mathrm{H}_{2} \mathrm{O}$ was firstly dissolved in $10 \mathrm{~mL}$ of deionized water under magnetic stirring to obtain a dark green solution, and then $0.76 \mathrm{~g}$ of $\mathrm{NaBH}_{4}$ was poured into the above solution while slowly stirring for another $20 \mathrm{~min}$ until no bubbles were generated from the solution. The as-prepared $\mathrm{Cr}(\mathrm{OH})_{3}$ precursor was collected by centrifugation, followed by washing with ethanol. Secondly, $2 \mathrm{~g}$ of $\gamma-\mathrm{Al}_{2} \mathrm{O}_{3}$ and a certain amount of $\mathrm{Ca}\left(\mathrm{NO}_{3}\right)_{2}$ were added into the alkali solution of the prepared $\mathrm{Cr}(\mathrm{OH})_{3}$ products under magnetic stirring to form a homogeneous suspension. Finally, the suspension was dried at $100{ }^{\circ} \mathrm{C}$ overnight and then calcined at $600{ }^{\circ} \mathrm{C}$ for $6 \mathrm{~h}$. The prepared catalysts with the Ca doping amounts of $0,1,2$ and $4 \mathrm{wt} \%$ were denoted as $\mathrm{Cr} / \gamma-\mathrm{Al}_{2} \mathrm{O}_{3}$, $\mathrm{Ca} 1-\mathrm{Cr} / \gamma-\mathrm{Al}_{2} \mathrm{O}_{3}, \mathrm{Ca} 2-\mathrm{Cr} / \gamma-\mathrm{Al}_{2} \mathrm{O}_{3}$ and $\mathrm{Ca} 4-\mathrm{Cr} / \gamma-\mathrm{Al}_{2} \mathrm{O}_{3}$, respectively.

\subsection{Samples Characterization}

The powder X-ray diffraction (XRD) patterns of the catalysts were recorded on a Siemens D5000 $\left(\mathrm{Cu} \mathrm{K} \alpha\right.$ radiation, range $2 \theta=10-90^{\circ}$, Siemens, Germany). The pore texture of the catalysts was evaluated by low-temperature N2 adsorption-desorption on a 3H-2000PS2 apparatus (Bei Shi De, Beijing, China). Before the test, samples were degassed at $150{ }^{\circ} \mathrm{C}$ for $4 \mathrm{~h}$. The total pore volume was calculated as $\mathrm{P} / \mathrm{P0}=0.993$, and the surface areas of the samples were derived by the BET (Brunauer-Emmett-Teller) method. A scanning election microscope (SEM, JEOL JSM-7500F, Tokyo, Japan) was employed to investigate the morphologies of the prepared catalysts. The acidity properties of catalysts were evaluated by the temperature-programmed desorption of ammonia $\left(\mathrm{NH}_{3}-\mathrm{TPD}\right)$ on an ASAP 2010C (Micromeritics, Norcross, GA, USA) apparatus at ambient pressure. About $0.15 \mathrm{~g}$ of the catalyst was placed into a quartz reactor and saturated with ammonia at room temperature. The $\mathrm{NH}_{3}$-TPD test was carried out from 50 to $700{ }^{\circ} \mathrm{C}$ with a heating rate of $10{ }^{\circ} \mathrm{C} \mathrm{min}-1$. Temperature-programmed reduction (TPR) profiles were obtained on an ASAP 2010C apparatus (Micromeritics, Norcross, GA, USA). The samples were dried in an $\mathrm{N}_{2}$ flow $\left(30 \mathrm{~mL} \mathrm{~min}^{-1}\right)$ at $400{ }^{\circ} \mathrm{C}$ for $2 \mathrm{~h}$. Then, $5 \mathrm{vol} \%$ $\mathrm{H}_{2} / \mathrm{N}_{2}\left(30 \mathrm{~mL} \mathrm{~min}^{-1}\right.$ ) was introduced as the reduction gas with the temperature from 50 to $800{ }^{\circ} \mathrm{C}$ at a heating rate of $10^{\circ} \mathrm{C} \mathrm{min}^{-1}$. The Thermogravimetry (TG) tests were carried out on a NERZSOH STA 409 thermal analyzer (NETZSCH, Hanau, German) to investigate the amount of coke deposited on the spent catalysts. The TG curves were obtained from room temperature to $800^{\circ} \mathrm{C}$.

\subsection{Catalytic Activity Evaluation}

The dehydrogenation of isobutane to isobutene reaction was performed in a continuous flow fixed-bed micro-reactor under atmospheric pressure. $5 \mathrm{~g}$ of the prepared catalyst was located into the center of the micro-reactor, which was heated to $550{ }^{\circ} \mathrm{C}$ under $\mathrm{N}_{2}$ stream $\left(30 \mathrm{~mL} \mathrm{~min}^{-1}\right)$ for $2 \mathrm{~h}$. Then, the undiluted isobutane gas as a raw material $\left(40 \mathrm{~mL} \mathrm{~min}^{-1}\right)$ was introduced into the reactor through the regulation of the mass flow controller. Reaction products were sequentially analyzed with an on-line gas chromatograph (SP-6890) equipped with a hydrogen flame ionization detector (FID). The equations for calculating the conversion rate of isobutane and the selectivity of isobutene are described as follows:

$$
\mathrm{i}-\mathrm{C}_{4} \mathrm{H}_{10} \text { conversion }=\left(\frac{\mathrm{i}-\mathrm{C}_{4} \mathrm{H}_{10 \text { in }}-\mathrm{i}-\mathrm{C}_{4} \mathrm{H}_{10 \text { out }}}{\mathrm{i}-\mathrm{C}_{4} \mathrm{H}_{10 \text { in }}}\right) \times 100 \%
$$




$$
\text { i- } \mathrm{C}_{4} \mathrm{H}_{8} \text { selectivity }=\left(\frac{\mathrm{i}-\mathrm{C}_{4} \mathrm{H}_{80 u t}}{\mathrm{i}-\mathrm{C}_{4} \mathrm{H}_{10 \text { in }}-\mathrm{i}-\mathrm{C}_{4} \mathrm{H}_{100 u t}}\right) \times 100 \%
$$

\section{Conclusions}

The Ca-doped $\mathrm{CrO}_{x} / \gamma-\mathrm{Al}_{2} \mathrm{O}_{3}$ catalysts with a $\mathrm{Cr}$ loading of $10 \mathrm{wt} \%$ were fabricated via the one-pot method by employing $\mathrm{Cr}(\mathrm{OH})_{3}$ as the precursor. The results of catalytic activity tests indicated that the Ca-doped catalysts exhibited a superior catalytic performance for the dehydrogenation of the isobutane to isobutene process in comparison with the undoped catalyst. The $\mathrm{Ca} 2-\mathrm{Cr} / \gamma-\mathrm{Al}_{2} \mathrm{O}_{3}$ catalyst with the optimum Ca doping of $2 \mathrm{wt} \%$ possessed the stable and highest selectivity of isobutene $(>83 \%)$ under the investigation time. The introduction of the Ca element into the $\mathrm{CrO}_{x} / \gamma-\mathrm{Al}_{2} \mathrm{O}_{3}$ catalysts results in the optimum acid strength as well as an enhanced interaction between the active species and the support, thus leading to the improved selectivity of isobutene as well as the conversion of isobutane.

Author Contributions: Conceptualization, G.W.; methodology, D.H.; investigation, N.S., K.L.; data curation, L.B.; methodology, F.W.; writing—original draft preparation, N.S., D.H.; writing—review and editing, W.W., Q.Z., H.F.; supervision, D.H.; project administration, G.W.

Funding: This research was funded by National Natural Science Foundation of China $(51803107,51602297)$, Postdoctoral Innovation Program of Shandong Province (201603043), Natural Science Foundation of Shandong (ZR2018027, ZR2019BB052), Fund of the State Key Laboratory of Chemical Resource Engineering, Beijing University of Chemical Technology (CRE-2018-C-3-2), Key Research and Development Project of Shandong Province (2019GGX103018, 2016ZDJS11A04) and Start-up Foundation for Advanced Talents of Qingdao University of Science and Technology (010022919).

Conflicts of Interest: The authors declare no conflict of interest.

\section{References}

1. Nawaz, Z. Light alkane dehydrogenation to light olefin technologies: A comprehensive review. Rev. Chem. Eng. 2015, 31, 413-436. [CrossRef]

2. Ren, Y.; Liao, Z.; Sun, J.; Jiang, B.; Wang, J.; Yang, Y.; Wu, Q. Molecular reconstruction: Recent progress toward composition modeling of petroleum fractions. Chem. Eng. J. 2019, 357, 761-775. [CrossRef]

3. Symoens, S.H.; Olahova, N.; Gandarillas, A.E.M.; Karimi, H.; Djokic, M.R.; Reyniers, M.F.; Marin, G.B.; Geem, K.M.V. State-of-the-art of coke formation during steam cracking: Anti-coking surface technologies. Ind. Eng. Chem. Res. 2018, 57, 16117-16136. [CrossRef]

4. Qiao, K.; Peng, P.; Hu, C.; Bai, P.; Yan, Z. Synthesis of vanadium-based catalysts and their excellent catalytic behaviors on dehydrogenation of C4 hydrocarbons. Appl. Petrochem. Res. 2015, 5, 321-327. [CrossRef]

5. Galvis, H.M.T.; Jong, K.P.D. Catalysts for production of lower olefins from synthesis gas: A review. ACS Catal. 2013, 3, 2130-2149. [CrossRef]

6. Zhou, S.; Zhou, Y.; Shi, J.; Zhang, Y.; Sheng, X.; Zhang, Z. Synthesis of Ce-doped mesoporous $\gamma$-alumina with enhanced catalytic performance for propane dehydrogenation. J. Mater. Sci. 2015, 50, 3984-3993. [CrossRef]

7. Sattler, J.J.H.B.; Ruiz-Martinez, J.; Santillan-Jimenez, E.; Weckhuysen, B.M. Catalytic dehydrogenation of light alkanes on metals and metal oxides. Chem. Rev. 2014, 114, 10613-10653. [CrossRef]

8. Rahimi, N.; Karimzadeh, R. Catalytic cracking of hydrocarbons over modified ZSM-5 zeolites to produce light olefins: A review. Appl. Catal. A Gen. 2011, 398, 1-17. [CrossRef]

9. Merk, A.A.; Salaev, M.A.; Vodyankina, O.V.; Mamontov, G.V. Influence of method of introduction of $\mathrm{Cu}$-and $\mathrm{Zn}$-based modifiers on the properties of chromia-alumina catalysts. Kinet. Catal. 2018, 59, $211-217$. [CrossRef]

10. McFarland, E. Unconventional chemistry for unconventional natural gas. Science 2012, 338, 340-342. [CrossRef]

11. Sheintuch, M.; Nekhamkina, O. Architecture alternatives for propane dehydrogenation in a membrane reactor. Chem. Eng. J. 2018, 347, 900-912. [CrossRef]

12. Farsi, M.; Jahanmiri, A.; Rahimpour, M.R. Optimal conditions of isobutane dehydrogenation in radial flow moving bed hydrogen-permselective membrane reactors to enhance isobutene and hydrogen production. Chem. Eng. Process. 2014, 75, 126-133. [CrossRef] 
13. Ma, Z.; Mo, Y.; Li, J.; An, C.; Liu, X. Optimization of $\mathrm{PtSnK} / \mathrm{Al}_{2} \mathrm{O}_{3}$ isobutane dehydrogenation catalyst prepared by an impregnation-reduction method. J. Nat. Gas Sci. Eng. 2015, 27, 1035-1042. [CrossRef]

14. Kilicarslan, S.; Dogan, M.; Dogu, T. Cr Incorporated MCM-41 type catalysts for isobutane dehydrogenation and deactivation mechanism. Ind. Eng. Chem. Res. 2013, 52, 3674-3682. [CrossRef]

15. Tian, Y.P.; Bai, P.; Liu, S.M.; Liu, X.M.; Yan, Z.F. $\mathrm{VO}_{x}-\mathrm{K}_{2} \mathrm{O} / \gamma-\mathrm{Al}_{2} \mathrm{O}_{3}$ catalyst for nonoxidative dehydrogenation of isobutene. Fuel Process. Technol. 2016, 151, 31-39. [CrossRef]

16. Wang, G.; Sun, N.; Gao, C.; Zhu, X.; Sun, Y.; Li, C.; Shan, H. Promoting mechanism of sulfur addition in catalytic dehydrogenation of isobutane over $\mathrm{Mo} / \mathrm{MgAl}_{2} \mathrm{O}_{4}$ catalysts. Appl. Catal. A Gen. 2014, 478, 71-80. [CrossRef]

17. Zhao, H.; Song, H.; Chou, L. Synthesis and catalytic application in isobutane dehydrogenation of the mesoporous chromia/alumina catalysts based on a metal-organic framework. Microporous Mesoporous Mater. 2013, 181, 182-191. [CrossRef]

18. Bugrova, T.A.; Mamontov, G.V. The Study of $\mathrm{CrO}_{x}$-containing catalysts supported on $\mathrm{ZrO}_{2}, \mathrm{CeO}_{2}$, and $\mathrm{Ce}_{\mathrm{x}} \mathrm{Zr}_{(1-\mathrm{x})} \mathrm{O}_{2}$ in isobutane dehydrogenation. Kinet. Catal. 2018, 59, 143-149. [CrossRef]

19. Matveyeva, A.N.; Zaitseva, N.; Mäki-Arvela, P.; Aho, A.; Bachina, A.; Fedorov, S.P.; Murzin, D.Y.; Pakhomov, N. Fluidized-bed isobutane dehydrogenation over alumina-supported $\mathrm{Ga}_{2} \mathrm{O}_{3}$ and $\mathrm{Ga}_{2} \mathrm{O}_{3}-\mathrm{Cr}_{2} \mathrm{O}_{3}$ catalysts. Ind. Eng. Chem. Res. 2018, 57, 927-938. [CrossRef]

20. Li, P.P.; Lang, W.Z.; Xia, K.; Luan, L.; Yan, X.; Guo, Y.J. The promotion effects of Ni on the properties of Cr/Al catalysts for propane dehydrogenation reaction. Appl. Catal. A Gen. 2016, 522, 172-179. [CrossRef]

21. Cavani, F.; Koutyrev, M.; Trifiro, F.; Bartolini, A.; Ghisletti, D.; Iezzi, R.; Piero, G.D. Chemical and physical characterization of alumina-supported chromia-based catalysts and their activity in dehydrogenation of isobutane. J. Catal. 1996, 158, 236-250. [CrossRef]

22. Neri, G.; Pistone, A.; Rossi, S.D.; Rombi, E.; Milone, C.; Galvagno, S. Ca-doped chromium oxide catalysts supported on alumina for the oxidative dehydrogenation of isobutene. Appl. Catal. A Gen. 2004, 260, 75-86. [CrossRef]

23. Korhonen, S.T.; Airaksinen, S.M.K.; Bañares, M.A.; Krause, A.O.I. Isobutane dehydrogenation on zirconia-, alumina-, and zirconia/alumina-supported chromia catalysts. Appl. Catal. A Gen. 2007, 333, 30-41. [CrossRef]

24. Martyanov, I.; Sayari, A. Sol-gel assisted preparation of chromia-silica catalysts for non-oxidative dehydrogenation of propane. Catal. Lett. 2008, 126, 164-172. [CrossRef]

25. Tsyganok, A.; Green, R.G.; Giorgi, J.B.; Sayari, A. Non-oxidative dehydrogenation of ethane to ethylene over chromium catalysts prepared from layered double hydroxide precursors. Catal. Commun. 2007, 8, $2186-2193$. [CrossRef]

26. Xu, L.; Wang, Z.; Song, H.; Chou, L. Catalytic dehydrogenation of isobutane over ordered mesoporous $\mathrm{Cr}_{2} \mathrm{O}_{3}-\mathrm{Al}_{2} \mathrm{O}_{3}$ composite oxides. Catal. Commun. 2013, 35, 76-81. [CrossRef]

27. Bai, Y.K.; Zheng, R.T.; Gu, Q.; Wang, J.J.; Wang, B.S.; Cheng, G.A.; Chen, G. One-step synthesis of hollow $\mathrm{Cr}(\mathrm{OH})_{3}$ micro/nano-hexagonal pellets and the catalytic properties of hollow $\mathrm{Cr}_{2} \mathrm{O}_{3}$ structures. J. Mater. Chem. A 2014, 2, 12770-12775. [CrossRef]

28. Shee, D.; Sayari, A. Light alkane dehydrogenation over mesoporous $\mathrm{Cr}_{2} \mathrm{O}_{3} / \mathrm{Al}_{2} \mathrm{O}_{3}$ catalysts. Appl. Catal. A Gen. 2010, 389, 155-164. [CrossRef]

29. Tom, W.D.; Carlos, H.M.; Krijn, P.J. Control of metal-support interactions in heterogeneous catalysts to enhance activity and selectivity. Nat. Catal. 2019, 2, 955-970.

30. Tigran, M.; Kim, L.; Sung, M.K.; Frank, K.; Alexey, F.; Peter, C.; Christoph, R.M.; Christophe, C. Molecularly Tailored Nickel Precursor and Support Yield a Stable Methane Dry Reforming Catalyst with Superior Metal Utilization. J. Am. Chem. Soc. 2017, 139, 6919-6927.

31. Jonathan, H.; Stephanie, L.; Rose, A.; Jason, S. The Impact of La Doping on Dry Reforming Ni-Based Catalysts Loaded on FSP-Alumina. Top. Catal. 2018, 61, 1842-1855.

32. Guangjian, W.; Xingyuan, S.; Xinshan, N.; Fanfei, M.; Fang, W. Effect of chelating agents on catalytic performance of $\mathrm{Cr} / \gamma-\mathrm{Al}_{2} \mathrm{O}_{3}$ dehydrogenation catalysts. Chem. Pap. 2018, 72, 921-928.

33. Han, D.; Li, X.; Zhang, L.; Wang, Y.; Yan, Z.; Liu, S. Hierarchically ordered meso/macroporous $\gamma$-alumina for enhanced hydrodesulfurization performance. Microporous Mesoporous Mater. 2012, 158, 1-6. [CrossRef]

34. Xing, T.; Wan, H.; Shao, Y.; Han, Y.; Xu, Z.; Zheng, S. Catalytic combustion of benzene over $\gamma$-alumina supported chromium oxide catalysts. Appl. Catal. A Gen. 2013, 468, 269-275. [CrossRef] 
35. Cheng, M.; Zhao, H.; Yang, J.; Zhao, J.; Yan, L.; Song, H.; Chou, L.J. The catalytic dehydrogenation of isobutane and the stability enhancement over Fe incorporated SBA-15. Microporous Mesoporous Mater. 2018, 266, 117-125. [CrossRef]

36. Lai, Y.; He, S.; Li, X.; Sun, C.; Seshan, K. Dehydrogenation of n-dodecane over PtSn/MgAlO catalysts: Investigating the catalyst performance while monitoring the products. Appl. Catal. A Gen. 2014, 469, 74-80. [CrossRef]

37. Narayanan, S.; Sultana, A.; Le, Q.T.; Auroux, A. A comparative and multitechnical approach to the acid character of templated and non-templated ZSM-5 zeolites. Appl. Catal. A Gen. 1998, 168, 373-384. [CrossRef]

38. Baek, J.; Yun, H.J.; Yun, D.; Choi, Y.; Yi, J. Preparation of highly dispersed chromium oxide catalysts supported on mesoporous silica for the oxidative dehydrogenation of propane using $\mathrm{CO}_{2}$ : Insight into the nature of catalytically active chromium sites. ACS Catal. 2012, 2, 1893-1903. [CrossRef]

39. Zhao, H.; Song, H.; Xu, L.; Chou, L. Isobutane dehydrogenation over the mesoporous $\mathrm{Cr}_{2} \mathrm{O}_{3} / \mathrm{Al}_{2} \mathrm{O}_{3}$ catalysts synthesized from a metal-organic framework MIL-101. Appl. Catal. A Gen. 2013, 456, 188-196. [CrossRef]

40. Fridman, V.Z.; Xing, R.; Severance, M. Investigating the $\mathrm{CrOx} / \mathrm{Al}_{2} \mathrm{O}_{3}$ dehydrogenation catalyst model: I. identification and stability evaluation of the $\mathrm{Cr}$ species on the fresh and equilibrated catalysts. Appl. Catal. A Gen. 2016, 523, 39-53. [CrossRef]

(C) 2019 by the authors. Licensee MDPI, Basel, Switzerland. This article is an open access article distributed under the terms and conditions of the Creative Commons Attribution (CC BY) license (http://creativecommons.org/licenses/by/4.0/). 